Brown, A. D. (1957). J. gen. Microbiol. 17, 640-648.

\title{
Some General Properties of a Psychrophilic Pseudo- monad: the Effects of Temperature on some of these Properties and the Utilization of Glucose by this Organism and Pseudomonas aeruginosa
}

\author{
By A. D. BROWN* \\ Commonwealth Scientific and Industrial Research Organization, \\ Division of Food Preservation and Transport, Queensland, Australia
}

SUMMARY: A psychrophilic species of the genus Pseudomonas was found to be capable of growth in a simple defined medium with any one of a number of carbon sources. The growth requirements were the same at $0^{\circ}$ and $20^{\circ}$. The organism vigorously oxidized glucose to gluconic and 2-ketogluconic acids. Rates of $\mathrm{O}_{2}$ uptake were measured over the range $0-40^{\circ}$ and compared with similar measurements on $P$. aeruginosa. Under the experimental conditions values of $\boldsymbol{Q}_{\mathrm{o}_{\mathbf{2}}}$ for the psychrophile were higher than those for $P$. aeruginosa at all temperatures, including those above $30^{\circ}$ at which temperatures the psychrophilic organism does not grow. The values of $Q_{\mathrm{O}_{2}}$ and their temperature coefficients were dependent on conditions of cultivation. It is concluded that the systems involved in the oxidation of glucose and gluconic acid by the two organisms may not be greatly different in those physical properties which determine their temperature relations.

Some types of bacteria which flourish under certain physical extremes, e.g. low water activities (the halophils) and high temperatures (the thermophiles) have been moderately well studied. Very little information about the physiology of the low-temperature bacteria (the psychrophils) is available, however. It is the purpose of the present report to describe some experiments undertaken to determine some general properties of a typical psychrophil, to compare some of these properties with those of a closely related mesophilic species and to suggest ways in which it might be possible to study the special properties of the psychrophil which enable it to thrive at low temperatures.

\section{METHODS}

Media. The following growth media were used:

Medium 1. 'General use' medium (Stephenson, 1949). An inorganic salts medium of concentration $0.057 \mathrm{M}$ and $\mathrm{pH} \mathrm{6.9}$, carbon source added as indicated.

Medium 2. 'Inorganic salts' medium of the following composition: $\left(\mathrm{NH}_{4}\right)_{2} \mathrm{SO}_{4}, 0.005 \mathrm{M} ; \mathrm{MgSO}_{4}, 0.005 \mathrm{M} ; \mathrm{Na}_{2} \mathrm{HPO}_{4}, 0.0126 \mathrm{M} ; \mathrm{KH}_{2} \mathrm{PO}_{4}, 0.0066 \mathrm{M}$; $\mathrm{NaCl}, 0.019 \mathrm{M} ; \mathrm{KCl}, 0.0114 \mathrm{M} ; \mathrm{Na}_{2} \mathrm{SO}_{4}, 0.0076 \mathrm{M} ; \mathrm{FeSO}_{4}, 0.0001 \mathrm{M}$. The final $\mathrm{pH}$ value was $7 \cdot 0$; carbon source added as indicated.

Medium 3. Hartley's tryptic digest broth (TDB).

Medium 4. 'Difco' Nutrient Broth (NB).

* Present address: Department of Bacteriology, University of Manchester. 
Modified Sørensen buffers containing $\mathrm{MgSO}_{4}$ were prepared to a molarity of $0 \cdot 057$ in the $\mathrm{pH}$ range $6 \cdot 1-7 \cdot 0$. Solutions of sugars and other organic compounds for use in these various media were prepared in $10 \%(\mathrm{w} / \mathrm{v})$ concentration and sterilized by filtration.

Organisms. A psychrophilic bacterium and a strain of Pseudomonas aeruginosa were used. The psychrophilic organism was isolated from chilled beef and is held in the stock culture collection of the Division of Food Preservation and Transport, C.S.I.R.O., Homebush, N.S.W., Australia, under the identification number 1482 . Stock cultures were maintained on nutrient agar at about $0^{\circ}$ with subsidiary cultures in TDB or NB.

For all purposes inocula were prepared by incubating the psychrophile in $6 \mathrm{ml}$. tubes of TDB or NB for 3 days at $20^{\circ}$ and Pseudomonas aeruginosa in $6 \mathrm{ml}$. tubes of $\mathrm{NB}$ overnight at $37^{\circ}$. Washed inocula were used in growth rate studies.

For growth rate studies $80 \mathrm{ml}$. of medium 1, or 60 ml. of medium 2 were dispensed in conical flasks of $200 \mathrm{ml}$. capacity, and agitated by a stream of sterile air. Samples were withdrawn through a side arm under pressure of the air stream. Growth rates were followed by colony counts or turbidimetrically. In the latter method turbidity was calibrated against the wet weight of cells.

Suspensions for manometric experiments were prepared by growing the organisms to their early stationary phase in Difco NB (1 l.) containing D-glucose $(0 \cdot 2 \%)$. The medium was seeded with $18 \mathrm{ml}$. of inoculum and incubated with occasional manual shaking. Pseudomonas aeruginosa was harvested after $25 \mathrm{hr}$. at $37^{\circ}$ or $69 \mathrm{hr}$. at $20^{\circ}$. The psychrophil was harvested after $69 \mathrm{hr}$. at $20^{\circ}$. The organisms were washed at $20^{\circ}$ in saline $(\mathrm{NaCl}, 0.3 \%, \mathrm{w} / \mathrm{v})$ and phosphate buffer $(0.057 \mathrm{M}, \mathrm{pH} \mathrm{7})$ and finally resuspended in water $(10 \mathrm{ml}$.$) at$ 0-5 ${ }^{\circ}$ for $30 \mathrm{~min}$.

Manometry. Rates of $\mathrm{O}_{2}$ uptake were determined in duplicate flasks by conventional Warburg techniques at the stated temperatures.

Analysis of cultures. For the analysis of reaction products, the organisms were grown in the aerating flasks in medium 1 containing D-glucose (1\%, $w / v)$ or washed suspensions were incubated under the same conditions in the phosphate buffer ( $\mathrm{pH} \mathrm{7}$ ) containing D-glucose (1\%). After centrifugation, cations were removed from the supernatant fluid by passage over the resin Amberlite IR-120. The effluent was neutralized to phenolphthalein with $\mathrm{NH}_{4} \mathrm{OH}$ and evaporated at $c .40^{\circ}$ under vacuum to $0.2-0.5 \mathrm{ml}$. Gluconic acid was identified first by paper chromatography at $20^{\circ}$ with the following solvent mixtures: $n$-butanol + acetic acid + water $(6+1+2) ; n$-propanol + ammonia solution sp.gr. $0 \cdot 880(6+4)$; water-saturated phenol. Its identity was confirmed by elution from the paper chromatogram and oxidation with $\mathrm{Fe}^{+++}$ ions and $\mathrm{H}_{2} \mathrm{O}_{2}$ (after Hockett \& Hudson, 1934) to a substance which was chromatographically indistinguishable from D-arabinose. 2-Ketogluconic acid was identified by its chromatographic behaviour in the above solvents, its reactions with ammoniacal silver nitrate (reduction), aniline phthalate (the pink of aldopentoses), its specific colour reaction with $O$-phenylene- 
diamine (Lanning \& Cohen, 1951) and by the chromatography of its 2:4-dinitro-phenylhydrazone in the butanol+acetic acid and propanol + ammonia solvent mixtures.

\section{RESULTS}

\section{General properties of the psychrophil}

The psychrophilic bacterium was a non-pigmented, monotrichous Pseudomonas sp. representative of the organisms to be described elsewhere by Brown \& Weidemann. It was capable of growth at $0^{\circ}$ and $20^{\circ}$ in medium 1 with any one of a number of simple carbon sources (Table 1). Growth did not occur at $37^{\circ}$ in either defined medium or Difco NB unless a trace (1 loopful) of the more complex TDB were added. Under such conditions or in TDB itself, restricted growth occurred.

\section{Table 1. Ability of the psychrophilic pseudomonad to utilize various substances for growth}

The numerals in parentheses refer to the number of days of incubation at $20^{\circ}$ for the appearance of definite turbidity in Medium $1+$ carbon source at $1 \%(w / v)$ concentration. Growth rates at $20^{\circ}$, determined by viable counts, were of similar magnitude with glucose, gluconate or succinate as carbon source.

$\begin{array}{llll}\text { D-Arabinose } & +(1-2) & \text { Citrate } & +(1-2) \\ \text { D-Glucose } & +(1-2) & \text { Fumarate } & +(1-2) \\ \text { Glycerol } & +(2-3) & \text { Gluconate } & +(1-2) \\ \text { Lactose } & - & \alpha \text {-Ketoglutarate } & +(1-2) \\ \text { Maltose } & - & \text { Succinate } & +(1-2) \\ \text { Sucrose } & - & & \\ \text { D-Xylose } & +(2-3) & & \end{array}$

Sodium malonate $(0.01 \mathrm{~m})$ had no effect on growth in medium 1 with any of the possible carbon sources. Sodium iodoacetate (0.001 $\mathrm{M})$ greatly inhibited growth and at $0.01 \mathrm{M}$ completely suppressed it. The rate of acid production from glucose was not affected by iodoacetate at either concentration.

\section{Quantitative observations}

Although qualitative observations had shown no absolute differences in nutrient requirements at $20^{\circ}$ and $0^{\circ}$ it was conceivable that there might be quantitative differences in relative growth rates and durations of the lag phase in complex and defined media. Table 2 summarizes results in which glycerol and D-glucose were used as separate carbon sources in basal medium 1 . It is evident that lowering the temperature from $20^{\circ}$ to $0^{\circ}$ affected growth rates in TDB and the glycerol medium about equally and somewhat less than in the glucose medium. The effect of the temperature change on the duration of the lag phase was less in defined medium no. 1 with both carbon sources than it was in the broth. Fig. 1 summarizes the effect of temperature over the range $0-40^{\circ}$ in a different medium (medium $2+1 \%(\mathrm{w} / \mathrm{v})$ glucose) on lag and growth rate of the psychrophil and Pseudomonas aeruginosa. 
Table 2. Rates of growth and durations of the lag phase of the psychrophilic pseudomonad at two temperatures in complex TDB medium and in defined media

\begin{tabular}{|c|c|c|c|}
\hline Medium & T.D.B. & $\begin{array}{c}\text { Defined } \\
\text { medium no. } \\
1+\text { glycerol } \\
(1 \%, w / v)\end{array}$ & $\begin{array}{c}\text { Defined } \\
\text { medium no. } \\
1+\text { glucose } \\
(1 \text { and } \\
2 \%, w / v)^{*}\end{array}$ \\
\hline $\begin{array}{l}20^{\circ} \text { lagt }(\mathrm{hr} . \pm 10 \%) \\
\text { Growth rate (gen./hr.) }\end{array}$ & $\begin{array}{l}3 \\
0 \cdot 75\end{array}$ & $\begin{array}{l}14 \\
0 \cdot 50\end{array}$ & $\begin{array}{c}18 \cdot 5 \\
0 \cdot 83\end{array}$ \\
\hline $\begin{array}{l}0^{\circ} \text { lagt }(\mathrm{hr} . \pm 10 \%) \\
\text { Growth rate (gen./hr.) }\end{array}$ & $\begin{array}{l}55 \\
0 \cdot 078\end{array}$ & $\begin{array}{l}108 \\
0 \cdot 061\end{array}$ & $\begin{array}{r}127 \\
0.060\end{array}$ \\
\hline $\begin{array}{l}\text { Ratio, } \operatorname{lag} 0^{\circ}: 20^{\circ} \\
\text { Growth rate } 20^{\circ}: 0^{\circ}\end{array}$ & $\begin{array}{l}18 \\
9 \cdot 6\end{array}$ & $\begin{array}{l}7 \\
8 \cdot 2\end{array}$ & $\begin{array}{c}9 \\
13 \cdot 8\end{array}$ \\
\hline
\end{tabular}

* Variations of this magnitude in glucose concentration had no effect on either lag or growth rate.

$\dagger$ Defined as the length of the straight line drawn parallel to the time axis through the logarithm of the population at time zero to the point of intersection with the straight line representing the logarithmic growth phase. Growth was followed by viable counts.

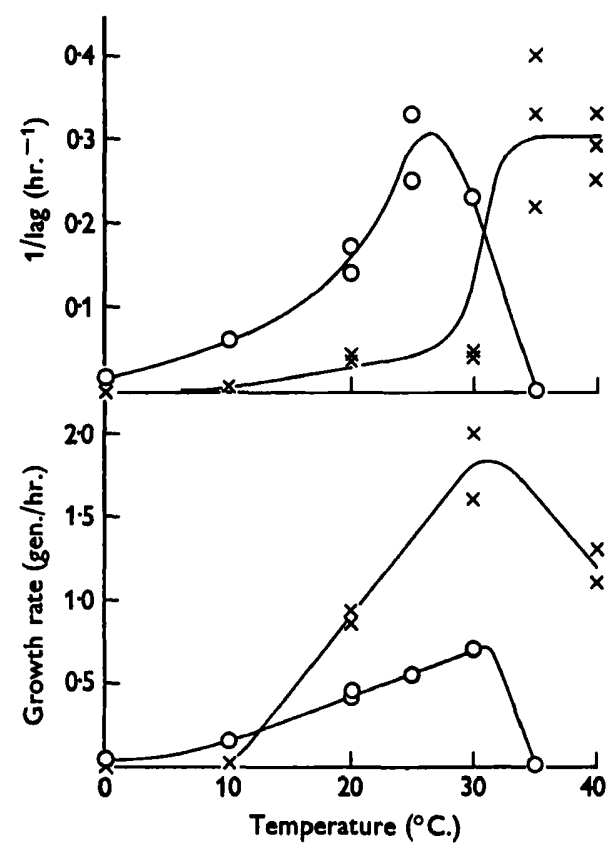

Fig. 1. The effects of temperature on the duration of the lag phase (upper figure) and on growth rate (lower figure) of Pseudomonas aeruginosa $(x)$ and the psychrophil $(0)$. Growth was followed turbidimetrically in medium 2 containing glucose (1\%). Inocula were the contents of $6 \mathrm{ml}$. culture in 'Difco' Nutrient broth centrifuged and resuspended in water $(1 \mathrm{ml}$.). (Note that absolute values of growth rate of the psychrophil were less in this medium than for example, in medium 1, see Table 2.) 


\section{Observations on glucose utilization}

The production of acid. At $20^{\circ}$, under conditions of relatively vigorous aeration either during growth in defined medium or during incubation of a washed suspension in a buffer, the psychrophil produced acid from excess glucose $(1 \%$ ) until an acid concentration equivalent to $\mathrm{pH} \mathrm{3.0-3.2}$ was obtained. At this stage growth and further breakdown of the acids so produced ceased. At $0^{\circ}$ the lowest $\mathrm{pH}$ values recorded under similar conditions were of the order of 4 . With lower initial concentrations of glucose (e.g. $0.5 \%$ ) such low pH values were not reached, and after the exhaustion of the glucose supply the acidic reaction products were utilized, accompanied by an increase of $\mathrm{pH}$ value of the medium and further growth. Under similar conditions, but at $37^{\circ}$, the lowest $\mathrm{pH}$ value reached with Pseudomonas aeruginosa was 4.8-4.9. At $0^{\circ}$ no change in the $\mathrm{pH}$ value of medium 1 or the buffer was detected after a month's incubation of $P$. aeruginosa in the presence of glucose. During this time the suspension became sterile but the dead organisms retained their ability to oxidize glucose to acid on rewarming to $37^{\circ}$. The identity of these acids was the same as produced by viable organisms (see next section).

The rates of acid production from glucose by a washed suspension of the psychrophile in phosphate buffer $(\mathrm{pH} 7)$ were: at $20^{\circ}, 0.96 \times 10^{-5} \mathrm{~g}$. equiv. $\mathrm{H}^{+} / \mathrm{mg}$. dry wt. organism $/ \mathrm{hr}$; at $0^{\circ}, 1.07 \times 10^{-6} \mathrm{~g}$. equiv. $\mathrm{H}^{+} / \mathrm{mg}$. dry wt. organism/hr., the temperature coefficient (ratio $20^{\circ}: 0^{\circ}$ ) being $9 \cdot 0$. A degree of lysis (28-48\%) occurred at both temperatures shortly after the preparation of the suspension in the buffer. The above rates were expressed on the initial weight of organism in the buffer, i.e. before lysis. When rates are expressed on weight of whole organisms after lysis had ceased the corresponding temperature coefficient is $\mathbf{7 \cdot 5}$.

The identity of the acids formed. The only substances found to accumulate in the medium from oxidation of glucose at $20^{\circ}$ and $0^{\circ}$ by the psychrophil were gluconic and 2-ketogluconic acids. Volatile acids were not specifically sought and the conditions of cultivation and analysis were such that very volatile acids, e.g. formic and acetic acids, would have escaped detection. No organic phosphates were detected on chromatograms with the molybdate reagent described by Hanes \& Isherwood (1949). In the presence of iodoacetate $(0.005 \mathrm{M})$ a substance which behaved chromatographically as glycollic acid also accumulated.

Many studies with the mesophilic species of Pseudomonas have established the accumulation of gluconic and 2-ketogluconic acids (see reviews by Gunsalus, Horecker \& Wood, 1955; Wood, 1955). It was confirmed that the strain of $\boldsymbol{P}$. aeruginosa used in the present work also accumulated these substances at $20^{\circ}$ and $37^{\circ}$ but, as would be expected from the foregoing measurements of $\mathrm{pH}$ value, in lower concentration than produced by the psychrophil. (As no attempt was made to neutralize the acids as they were formed this difference is probably merely an indication of differences in acid tolerance.) 
Manometric measurements. Preliminary observations were made at $\mathbf{3 0}^{\circ}$ with Pseudomonas aeruginosa and at $2^{\circ}$ with the psychrophil. Under these conditions whole organisms of $\boldsymbol{P}$. aeruginosa oxidized glucose and gluconate with total uptakes of 5 and 4.5 mole $\mathrm{O}_{2} /$ mole glucose and gluconate, respectively. The psychrophil used 4.5 and 4 mole $\mathrm{O}_{2} /$ mole glucose and gluconate, respectively. The effect of $\mathrm{pH}$ value on rate of $\mathrm{O}_{2}$ uptake was determined in the range $\mathrm{pH} 6 \cdot 1-7 \cdot 0$. P. aeruginosa oxidized glucose at the same rate throughout this range but oxidized gluconate fastest at $\mathrm{pH} 6 \cdot 1$. The mean and total range of rates of two or three measurements of $Q_{0_{2}}$ with this substrate at these limits of $\mathrm{pH}$ were $Q_{0}, 83 \pm 9$ and $72 \pm 7$, at $\mathrm{pH} 6 \cdot 1$ and 7 respectively. The psychrophil also oxidized gluconate fastest at $\mathrm{pH} 6 \cdot 1\left(Q_{0}, 178 \pm 25\right.$ and $157 \pm 18$ at $\mathrm{pH} 6 \cdot 1$ and 7 , respectively), but glucose was oxidized most rapidly at $\mathrm{pH} 7 \cdot 0$ (see Fig. 2).

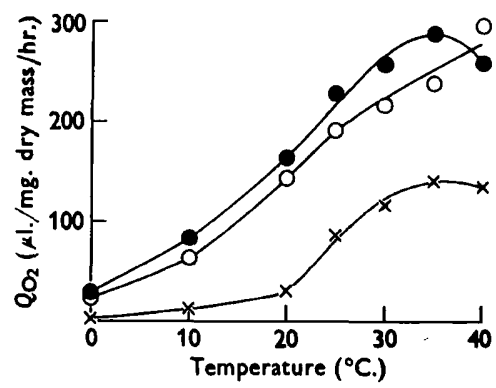

Fig. 2

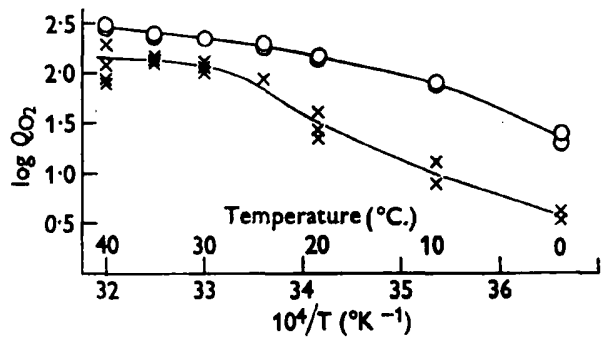

Fig. 3

Fig. 2. The effect of temperature on $Q_{0_{2}}$ in the presence of glucose for the psychrophil at $\mathrm{pH} 7(\bullet)$ and $\mathrm{pH} \mathrm{6.1} \mathrm{(0)} \mathrm{and} \mathrm{for} \mathrm{Pseudomonas} \mathrm{aeruginosa}(x)$ at $\mathrm{pH}$ 6.1. The respiration flask contained phosphate buffer $(1.0 \mathrm{ml}$.), cell suspension (1.58 mg. dry mass $/ \mathrm{ml}$.; $1.7 \mathrm{ml}$.), substrate (0.556 $\mathrm{M} ; 0.3 \mathrm{ml}$.) with $\mathrm{KOH}$ in the centre cup. Endogenous respiration has been subtracted. The points represent means of the replicates shown in Fig. 3 . Similar results, but with lower overall values of $Q_{0_{2}}$, were obtained when sodium gluconate was the substrate.

Fig. 3. $\log Q_{\mathrm{O}_{2}}$ with glucose at $\mathrm{pH} \mathrm{6.1} \mathrm{v.} \mathrm{the} \mathrm{reciprocal} \mathrm{of} \mathrm{the} \mathrm{absolute} \mathrm{temperature} \mathrm{(T)}$ for the psychrophil $(O)$ and for Pseudomonas aeruginosa $(x)$. Corresponding curves for sodium gluconate have a somewhat more obvious change in slope near $30^{\circ}$ in the case of $P$, aeruginosa and lower overall values of $\log Q_{\mathrm{O}_{2}}$.

The effects of temperature on oxygen uptake rates were determined at pH 6.1 with additional measurements at $\mathrm{pH} 7$ for oxidation of glucose by the psychrophil. The results of these measurements are shown in Fig. 2, from which it is apparent that under the experimental conditions the psychrophil was capable of utilizing the two substrates more vigorously than Pseudomonas aeruginosa. This greater activity was displayed at all temperatures including those above the maximum at which the psychrophil can grow. Reference to Fig. 3 also shows a different effect of temperature over the range $0-40^{\circ}$ on the processes in the two organisms. These logarithmic curves show in the case of $P$. aeruginosa a relatively sudden change in slope near $30^{\circ}$. No corresponding changes in slope are apparent in the curves for the psychrophil. 
The effect of growth temperature on $Q_{\mathrm{o}_{2}}$ of Pseudomonas aeruginosa. In order to assess the effect of growth temperature on ability to oxidize the two substrates, $P$. aeruginosa was grown for $69 \mathrm{hr}$. at $20^{\circ}$ and the rates of $\mathrm{O}_{2}$ uptake measured at $0^{\circ}$ and $20^{\circ}$. The results are given in Table 3 . It will be seen that growth at the lower temperature led to greater values of $Q_{\mathrm{O}_{2}}$ at both temperatures, a decreased temperature coefficient over this range and a changed $\mathrm{pH}$ relationship for the oxidation of glucose. Thus, when grown under identical conditions, the two organisms resembled each other more closely. $P$. aeruginosa, which had been grown in this way at $20^{\circ}$ would not, however, grow at $0^{\circ}$.

Table 3. The effect of growth temperature on rates of $\mathrm{O}_{2}$ uptake by Pseudomonas aeruginosa

\begin{tabular}{|c|c|c|c|c|c|c|c|c|}
\hline \multirow{4}{*}{$\begin{array}{l}\text { Incubation } \\
\text { temperature } \\
\text { of } \\
\text { suspension }\end{array}$} & \multicolumn{5}{|c|}{ P. aeruginosa } & \multirow{2}{*}{\multicolumn{3}{|c|}{$\begin{array}{l}\text { Psychrophilic } \\
\text { pseudomonad. } \\
\text { Grown at } 20^{\circ}\end{array}$}} \\
\hline & \multirow{2}{*}{\multicolumn{2}{|c|}{ Grown at $87^{\circ}$}} & \multicolumn{3}{|c|}{ Grown at $20^{\circ}$} & & & \\
\hline & & & \multicolumn{2}{|c|}{ Glucose } & \multirow[b]{2}{*}{$\begin{array}{l}\text { Gluco- } \\
\text { nate }\end{array}$} & \multicolumn{2}{|c|}{ Glucose } & \multirow[b]{2}{*}{$\begin{array}{c}\text { Gluco- } \\
\text { nate }\end{array}$} \\
\hline & $\begin{array}{l}\text { Glucose } \\
\text { pH 6.1 }\end{array}$ & $\begin{array}{l}\text { Gluco- } \\
\text { nate }\end{array}$ & pH 6.1 & $\widehat{\mathrm{pH} \mathrm{7.0}}$ & & $\overbrace{\mathrm{pH} \mathrm{6} 1}$ & $\mathrm{pH} \mathrm{7.0}$ & \\
\hline & \multicolumn{8}{|c|}{$Q_{\mathrm{O}_{\mathbf{\Omega}}}$ values } \\
\hline $\begin{array}{r}30^{\circ} \\
0^{\circ}\end{array}$ & $\begin{array}{l}118 \\
8 \cdot 8\end{array}$ & $\begin{array}{l}79 \\
1 \cdot 7\end{array}$ & $\begin{array}{r}185 \\
8 \cdot 3\end{array}$ & $\begin{array}{r}247 \\
12\end{array}$ & $\begin{array}{r}164 \\
11\end{array}$ & $\begin{array}{r}224 \\
22\end{array}$ & $\begin{array}{r}268 \\
29\end{array}$ & $\begin{array}{r}182 \\
20\end{array}$ \\
\hline $\begin{array}{l}\text { Temperature } \\
\text { coefficient } \\
\left(\text { ratio } 80^{\circ}: 0^{\circ}\right)\end{array}$ & 31 & 46 & 22 & 21 & 15 & 10 & $9 \cdot 2$ & $9 \cdot 1$ \\
\hline
\end{tabular}

\section{DISCUSSION}

It is evident that in respect of its growth requirements, its oxidative attack on glucose and its accumulation of reaction products, e.g. gluconic and 2-ketogluconic acids, the psychrophilic bacterium is typical of the genus Pseudomonas. The ease of growth on D-arabinose (Table 1) and the probable accumulation of glycollic acid in the presence of iodoacetate might be related to the reported breakdown of D-arabinose by $P$. saccharophila to give pyruvic and glycollic acids (Doudoroff, De Ley, Palleroni \& Weimberg, 1956). Thus nothing emerges from these observations which obviously distinguishes the psychrophil from other species which have been well studied to date, namely, $\boldsymbol{P}$. aeruginosa, $\boldsymbol{P}$. fluorescens, $\boldsymbol{P}$. saccharophila and $\boldsymbol{P}$. hydrophila.

Examination of the psychrophilic organism at $0^{\circ}$, however, did reveal some properties which might be characteristic of psychrophilic bacteria. Its simple growth requirements are not changed by lowering the temperature to $0^{\circ}$. Indeed, in respect of at least one property, namely the duration of the lag phase, it might be argued that $0^{\circ}$ is a more favourable temperature for this organism than $20^{\circ}$. The different temperature coefficients of the lag in defined media (no. 1) and TDB (Table 2) have the effect of decreasing the proportional differences between the lag phases in the two kinds of medium when the temperature is lowered to $0^{\circ}$. For example, at $20^{\circ}$ the lag in defined medium 
was about 4.5 times as great as in TDB, but at $0^{\circ}$ this ratio was reduced to about 2.

The comparisons of the growth rates and lags of the psychrophil and $P$ seudomonas aeruginosa (Fig. 1) show differences which might be indicative of more than a simple species difference and of the ways in which the inocula for these experiments were prepared. Notwithstanding the large measure of uncertainty which frequently accompanies measurements of lag it is clear that under the conditions used here at least, the psychrophil was able to begin multiplication much sooner than $\boldsymbol{P}$. aeruginosa over almost all of that part of the temperature range in which growth of both species occurred. This suggests that the psychrophil might be better able to adjust itself (no implications about the mechanism of adjustment are intended) to a new and potentially difficult environment than is $\boldsymbol{P}$. aeruginosa.

As the suspensions used in the manometric experiments were grown under similar conditions of time and temperature to those used in the comparisons presented in Fig. 1 it is conceivable that the higher rates of glucose oxidation by the psychrophil are related to its shorter lag phase. The difference in final concentrations of acid produced by the two species might reflect differences in the importance of some metabolic pathways of the two organisms or, more likely, it might merely reflect differences in acid tolerance. Whether these three features, namely a comparatively short lag phase in synthetic media, vigorous oxidative ability over a relatively wide range of temperature and possibly greater tolerance than the mesophilic species to $\mathrm{H}^{+}$are generally characteristic of the psychrophilic species of Pseudomonas has yet to be ascertained.

Table 3, however, shows that quantitative differences between the two organisms are subject to modification by variations in the growth conditions of the cells. It is probably reasonable to conclude that under certain conditions of growth the relevant enzymes in the two species might not be greatly different in respect of those physical properties which determine their temperature relations. If this is true it is clear that an explanation of the different temperature minima for growth must be sought elsewhere than in the initial stages of glucose oxidation, possibly in metabolic differences or in physical differences in some essential enzyme systems. It is apparent, however, that useful information is to be obtained from a study of simple systems which need not necessarily be essential to the growth of the organism. In such a study it is obviously desirable to compare these systems in organisms which have been grown under carefully selected conditions of temperature and time and to obtain evidence of the relative contributions of cellular organization on the one hand and the physical properties of the relevant enzymes on the other to results such as have been obtained already and are likely to be obtained after different conditions of growth.

The initial stages of this programme were undertaken at the Low Temperature Research Station, Cambridge. The facilities provided and the technical assistance of Mr J. Barlow are gratefully acknowledged. 


\section{REFERENCES}

Doudoroff, M., de Ley, J., Palleroni, N. J. \& Weimberg, R. (1956). New pathways in oxidation of D-galactose and of D-arabinose. Fed. Proc. 15, 794.

Gunsalus, I. C., Horecker, B. L. \& Wood, W. A. (1955). Pathways of carbohydrate metabolism in microorganisms. Bact. Rev. 19, 79.

HANES, C. S. \& Isherwood, F. A. (1949). Separation of the phosphoric esters on the filter paper chromatogram. Nature, Lond. 164, 1107.

HocketT, R. C. \& Hudson, C. S. (1934). Improvements in the preparation of D-arabinose from calcium gluconate. J. Amer. chem. Soc. 56, 1632.

Lanning, M. C. \& Conen, S. S. (1951). The detection and estimation of 2-ketohexonic acids. J. biol. Chem. 189, 109.

Stephenson, M. (1949). Bacterial Metabolism. 3rd ed. London: Longmans Green and Co.

Woon, W. A. (1955). Pathways of carbohydrate degradation in Pseudomonas fluorescens. Bact. Rev. 19, 222.

(Received 21 May 1957) 